\title{
periferio
}

\section{PERSPECTIVA CRÍTICA DA EDUCAÇÃO E REGULAÇÃO CURRICULAR: POSSIBILIDADES CONSTITUTIVAS DA AUTONOMIA DOCENTE}

\author{
Antonia Alves Pereira Silva ${ }^{1}$ \\ Universidade Estadual do Piauí
}

\section{Resumo}

Neste artigo discutimos a autonomia como princípio da prática docente situando esta reflexão a partir da perspectiva crítica da educação que influenciou o discurso sobre formação docente presente na literatura educacional e, em parte, os documentos legais sobre formação. Sustentamos, com Henry Giroux, Paulo Freire e Ilma P. Veiga, que a prática do professor deve ser pautada na capacidade crítico-reflexiva e na autonomia, dentre outros. As reformas educacionais iniciadas nos anos 1990 trazem uma concepção de regulação calcada nos parâmetros neoliberais que pretendem restringir a autonomia docente. Defendemos, à luz do conceito de esfera pública de Giroux e da Teoria da Atuação de Ball, possibilidades de escape à excessiva normatização do currículo e da prática docente via processos coletivos de participação.

Palavras-chave: formação docente; regulação; autonomia; resistência

\footnotetext{
1 Pedagoga. Professora Assistente III da Universidade Estadual do Piauí (UESPI). Doutoranda em Educação-ProPEd/UERJ. Bolsista da Fundação de Amparo à Pesquisa do Estado do PiauíFAPEPI/Capes. Membro do Núcleo de Estudos e Pesquisa em Educação e Sociedade (NEPES/UESPI) e Grupo de Pesquisa Políticas de Avaliação, Desigualdades e Educação Matemática (UERJ). antoniaalves0416@yahoo.com.br.
} 


\title{
periferio
}

\section{CRITICAL PERSPECTIVE OF CURRICULAR EDUCATION AND REGULATION: CONSTITUTIVE POSSIBILITIES OF TEACHER AUTONOMY}

\begin{abstract}
In this article, we discuss autonomy as a principle of teaching practice, situating this reflection from the critical perspective of education that influenced the discourse about teacher training present in the educational literature and, in part, the legal documents about formation. We hold, with Henry Giroux, Paulo Freire and IIma Veiga, that the teacher's practice should be based on critical-reflexive capacity and autonomy, among others. The educational reforms initiated in the 1990s bring a conception of regulation based on the neoliberal parameters that intend to restrict the teaching autonomy. We defend, basead on Giroux 's concept of the public sphere and Ball' s Theory of Action, possibilities of escaping the excessive normatization of the curriculum and teaching practice through collective processes of participation.
\end{abstract}

Keywords: teachear training; regulation; autonomy; resistance 


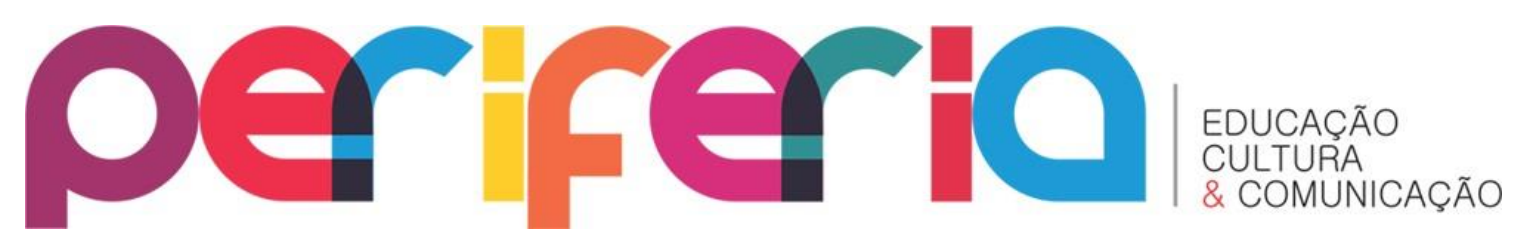

INTRODUÇÃO

A política educacional brasileira, partir dos anos 1990, é marcada por um conjunto de medidas que pretendiam promover uma reforma na educação do país em consonância com os acordos estabelecidos com os organismos internacionais multilaterais (SHIROMA; EVANGELISTA, 2015; FREITAS, 2014). Dentre essas medidas podem ser citadas a Lei de Diretrizes e Bases da Educação - Lei 9394/96, bem como as regulamentações dela advinda objetivando a redefinição da formação de professores, o estabelecimento de parâmetros curriculares nacionais e a criação de sistemas de avaliação em larga escala.

No discurso mobilizador das reformas está a construção de uma escola capaz de preparar o aluno para os novos desafios da sociedade contemporânea e globalizada (MOREIRA, 2013; SAUL, 2015). Nesse contexto a escola é desafiada à promoção de uma educação de qualidade que permita aos alunos o domínio de um conjunto de conhecimentos e habilidades necessários à sociedade globalizada. Assim, a formação de professores e o controle das práticas curriculares realizadas no âmbito das escolas são considerados estratégicos para obtenção da suposta qualidade na educação.

Dentre as políticas voltadas para educação básica que têm afetado diretamente o funcionamento escolar estão as que regulamentam a avaliação em larga escala. Seu impacto no sistema de ensino tem modificado currículos escolares e também refletido na formação e na prática docente (ORTIGÃO E PEREIRA, 2016; FREITAS, 2014). O conjunto de medidas situadas nos marcos das reformas educacionais iniciadas nos anos 1990 tem como base teórica o neoliberalismo para educação, enfatizando princípios de gerenciamento, regulação e controle das ações realizadas pela escola ajustando os currículos e as práticas docentes aos exames nacionais de larga escala.

Tal perspectiva confronta com a teoria crítica da educação que tem fundamentado o discurso de formação dos professores desde o início dos anos 


\section{periferio}

1980, com o propósito de formar profissionais com capacidade crítica, reflexivos e autônomos. Consideramos que são estes elementos de formação docente que estão ameaçados pelas reformas de inspiração neoliberal. Pretendemos, pois, argumentar aqui em favor da autonomia como elemento fundamental na formação e atuação dos professores e da necessidade de buscar estratégias para enfrentar a regulação na educação viabilizando práticas curriculares com espaço para o desenvolvimento da autonomia.

Inicialmente, trazemos algumas características da teoria crítica da educação e da concepção de professor nessa perspectiva, ressaltando-o como intelectual transformador e, portanto, com autonomia pedagógica. A seguir apresentamos a discussão sobre o sistema de avaliação em larga escola como um dos grandes motes das reformas educacionais, bem como as críticas a seu caráter regulamentar. Por fim, refletimos à luz do conceito de esfera pública de Giroux (1997) e da Teoria da Atuação de S. Ball (LOPES, 2016), sobre as possibilidades de escape à excessiva regulamentação das políticas educacionais.

\section{FORMAÇÃO DO EDUCADOR PARA UMA PERSPECTIVA CRÍTICA DA EDUCAÇÃO}

O surgimento das teorias críticas na educação tem início na segunda metade do século passado e se relacionam a uma série de movimentos de caráter social, político e cultural registrados em diversas parte do mundo que impactaram de forma diferenciada as sociedades onde se manifestaram. Como aspecto conceitual central nessas teorias está o questionamento da sociedade a partir de suas relações desiguais de produção e distribuição do capital, destacando como essas relações produzem um quadro de desigualdades socioeconômicas refletindo em todas as esferas da sociedade. Assim, a análise da problemática educacional passa a considerar os conflitos existentes na sociedade e a escola como uma instituição não alheia às questões macrossociais. Portanto, relações de poder, ideologia, conscientização, 


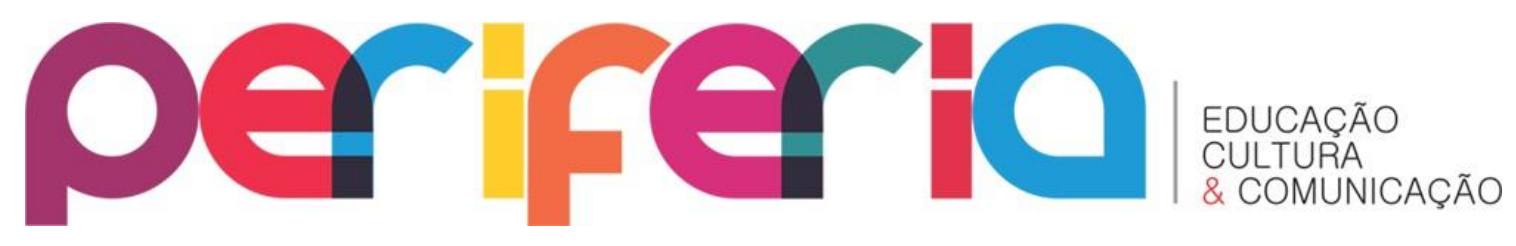

reprodução cultural, resistência e emancipação, passam a ocupar lugar de referência nos estudos educacionais. (SILVA, 2010).

No Brasil as teorias críticas passam a influenciar a produção educacional do país a partir dos anos 1980 com o processo redemocratização pós-ditadura militar, criando um quadro teórico que permite pensar a educação para além das questões micro escolares. Assim, a análise da problemática educacional passa a ser feita na inter-relação com os aspectos sociais, culturais, políticos e econômicos. No conjunto das teorias críticas produzidas nesse período é forjada uma concepção de formação de professores propondo, dentre outros, romper com a racionalidade técnica predominante na formação e atuação docente. A base inicial de influência dessa concepção de educação está tanto em autores internacionais como Michael Apple e Henry Giroux quanto em brasileiros como Paulo Freire, Dermeval Saviani, José Carlos Libâneo, Moacir Gadotti, Ilma Passos Veiga, dentre outros. Embora a temática da formação de professores não fosse preocupação inicial de alguns desses teóricos, o estudo do modo como as relações de poder e desigualdades se manifestam na prática educativa formal e informal (APPLE, AU e GANDIN, 2011), possibilitou uma ampla reflexão sobre a educação e o processo de formação de profissionais para atuar nessa área, entendida agora como um fenômeno complexo não neutro, portanto, campo de disputa de discursos hegemônicos (GIROUX, 1997).

Desse modo, o modelo de formação docente predominante até os anos 1980, de inspiração tradicional com sua vertente tecnicista, em que o professor era preparado para atuar como um técnico do processo educacional e sua função primordial era a de contribuir para formação da mão de obra necessária ao processo de industrialização, precisava ser modificado (BRZEZINSKI, 2002).

0 professor formado na perspectiva crítica da educação deveria estar comprometido com os princípios de democratização, justiça social e defesa da escola pública. Na defesa dessa concepção de professor convergem, além do pensamento dos teóricos mencionados, as universidades com autonomia, os 


\section{periferio}

intelectuais progressistas e entidades representativas da categoria como a Associação Nacional de Formação dos profissionais em Educação (ANFOPE).

Apresentamos, então, algumas ideias acerca da concepção crítica de professor para, na sequência, tensionar essa visão com as reformas educacionais iniciadas nos anos 1990. Uma das referências de formação na perspectiva crítica é trazida por Giroux (1997), que concebe os professores como profissionais intelectuais comprometidos com a transformação social e a emancipação. $O$ autor concebe o professor como intelectual numa oposição à visão tecnocrática na educação que separa o planejamento do trabalho de sua execução; o que no âmbito educacional implica colocar em pólos separados os que pensam o currículo daqueles que o executam. Giroux (1997) compreende a educação como política cultural e define os professores como intelectuais transformadores e não "[...] simplesmente como operadores profissionalmente preparados para atingirem quaisquer metas a eles apresentadas [...]". Em vez disso, propõe "encarar os professores como profissionais reflexivos" (p. 161). Desse modo, o trabalho do professor possui uma dimensão de atuação pautada na liberdade de ensinar e capacidade de questionar e de refazer a prática.

Para Giroux (1997) os intelectuais transformadores "precisam desenvolver um discurso que una a linguagem da crítica e a linguagem da possibilidade, de forma que os educadores sociais reconheçam que podem promover mudanças” (p. 161). Vemos aqui outra característica basilar no pensamento do autor, a educação como possibilidade de emancipação e o professor como agente dessa mudança. Nessa função de agente de mudança o professor deve manifestar-se contra as injustiças sociais e contribuir com o processo de cidadania dos estudantes. Em suas palavras, os professores como intelectuais,

Devem ser vistos em termos dos interesses políticos e ideológicos que estruturam a natureza do discurso e as relações sociais em sala de aula e valores que eles legitimam em sua atividade de ensino. Com essa perspectiva gostaria de 


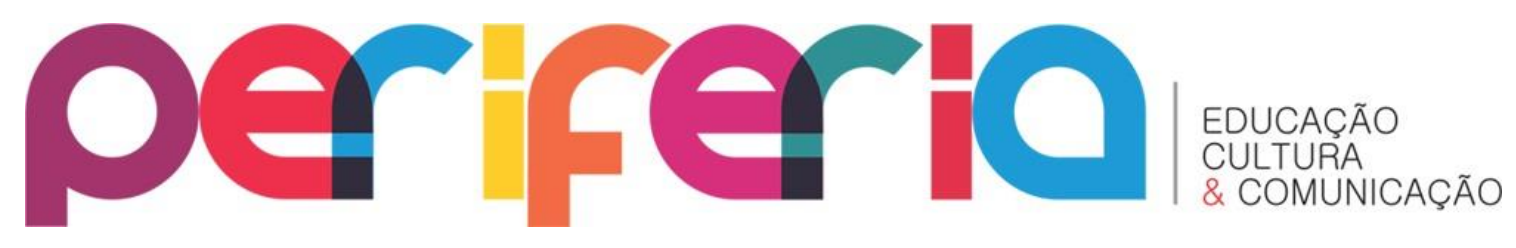

concluir que os professores deveriam se tornar intelectuais transformadores se quiserem educar os estudantes para serem cidadãos ativos e críticos. (GIROUX, 1997, p 162-163)

Esse modo de conceber a atuação do professor também está presente no pensamento de Paulo Freire, referência nas obras de Henri Giroux e Michael Apple. Para Freire (1987), o professor possui papel de mediador no processo de emancipação dos sujeitos através do conhecimento do mundo. Esse mundo, que é material e social, é desvelado no processo de interação dialógica entre os sujeitos/alunos e o professor. Para tanto, defende que “[...] na formação permanente dos professores, o momento fundamental é o da reflexão crítica sobre a prática. É pensando criticamente a prática de hoje ou de ontem que se pode melhorar a próxima prática". (FREIRE, 1996, p. 4344). Em seu pensamento a formação humana para a emancipação, só é possível em situação de dialogicidade, em que, não somente o professor, mas os estudantes tenham liberdade para expressar seu conhecimento do seu mundo: social, político e cultural. 0 conhecimento advém desse processo de descoberta do mundo social e de suas contradições e do indivíduo enquanto sujeito. Portanto, para Paulo Freire o ato educativo é um processo de humanização.

Verificamos tanto no pensamento de Giroux quanto de Freire que na prática do professor é imprescindível um sentido de autonomia pedagógica que se relaciona com o contexto social na busca de superação das desigualdades, injustiça social e a emancipação dos homens e mulheres. A compreensão da formação e atuação do professor nessa perspectiva é defendida também por outros autores que discutem o tema (BRZEZINSKI, 2002; VEIGA, 2012; BORGES, 2012). Veiga (2012) contrasta duas perspectivas de formação de professores, a primeira fundamentada em princípios da racionalidade técnica que forma o tecnólogo do ensino. A segunda é a do professor como agente social, em que educação "é concebida como uma prática social e um processo lógico de emancipação" (VEIGA, 2012, p 19). A autora propõe que a formação docente se desenvolva numa perspectiva de 


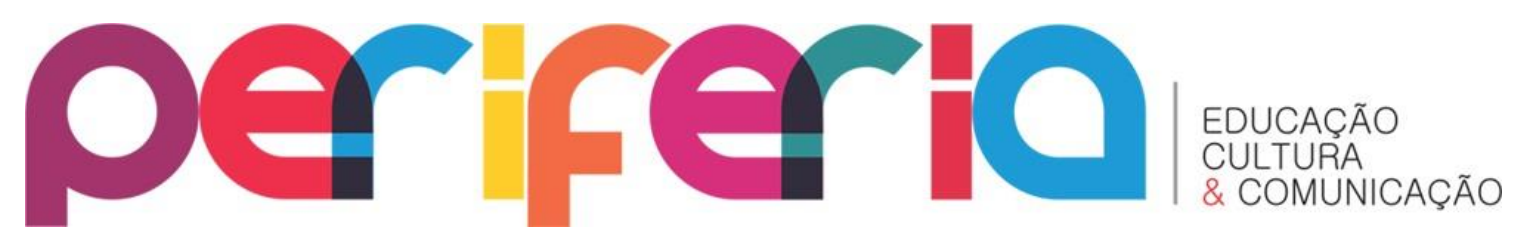

educação crítica e emancipadora discutindo vários aspectos inerentes a essa formação, dentre eles a autonomia que, segundo ela, "é vista como valor profissional do pensamento e da ação, aspirando a um maior controle sobre o trabalho pedagógico. Autonomia é entendida como processo coletivo solidário de busca de construção permanentes" (VEIGA, 2012, p 19).

No mesmo sentido, Borges (2012), apresenta três dimensões necessárias no processo de formação docente. A primeira é um arcabouço teórico e cultural específico da profissão docente demarcando sua epistemologia teórico-prática; a segunda considera que a construção desse repertório de conhecimento ocorre num tempo histórico determinado e resultado de relações entre sujeitos; e a terceira dimensão compreende a pesquisa como prática investigativa que reflete sobre a própria prática numa perspectiva de ampliação do conhecimento educacional. A autora salienta que para essa perspectiva é importante "a necessária autonomia docente, a qual é pensada como um processo em permanente construção, objeto de tensões imanentes nos ambientes educativos em que a relação entre sujeitos e instituições é permeada por valores e instâncias de poder". (BORGES, 2012, p. 40).

A autonomia docente, compreendida na perspectiva crítica, considera que os professores têm o autogoverno do seu trabalho; são os legítimos gestores do seu fazer pedagógico, são responsáveis pelo processo educacional, do planejamento à avaliação. Há, pois, um sentido de liberdade inerente ao trabalho docente autônomo. Entretanto, a ideia de autonomia carrega contradições e não deve ser tomada em termos absolutos. Gadotti (1999, p. 44) diz que "autonomia é um processo sempre inacabado, um horizonte em direção do qual podemos caminhar sempre sem nunca alcançá-la definitivamente". É, pois uma das utopias a ser perseguida pelos educadores críticos porque, conforme Snyders (1977 apud GADOTTI, 1999 p. 44), a autonomia relativa precisa ser mantida pela luta e "só pode tornar-se realidade se participar no conjunto das lutas das classes exploradas". Entender a autonomia em sentido não absoluto respeita a complexidade 


\section{periferio}

constituinte da educação. Não obstante, não invalida concebê-la como aspecto importante no processo formativo e na prática docente.

As percepções acerca da formação do professor aqui ilustradas se coadunam com uma concepção de prática desse futuro profissional, ou seja, o professor cujo processo formativo tenha sido pautado em princípio de autonomia pedagógica apreende esse saber como um dentre tantos outros saberes profissionais e pode situar sua prática também numa perspectiva de autonomia, contribuindo assim para formação também crítica e autônoma dos estudantes.

Não obstante a vasta produção intelectual acerca da formação crítica do professor e da compreensão da autonomia como essencial no seu trabalho, esse discurso não se faz predominante nos textos de políticas públicas de educação. A exemplo, a Resolução $n^{\circ}$ 2/2015 que define as Diretrizes Curriculares de Formação de Professores no Brasil, em nível superior, traz referências à autonomia e à emancipação em dois momentos: no Artigo $3^{\circ}$, Parágrafo $5^{\circ}$, Inciso II, ao tratar dos princípios da formação da formação dos profissionais do magistério e nos Artigos $5^{\circ}$ e $7^{\circ}$, ao tratar do egresso, sendo mais abrangente no Art. $5^{\circ}$, Inciso IV

\footnotetext{
A formação de profissionais do magistério deve assegurar a base comum nacional, pautada pela concepção de educação como processo emancipatório e permanente, [...] que se possa conduzir o(a) egresso(a):

IV - às dinâmicas pedagógicas que contribuam para o exercício profissional e o desenvolvimento do profissional do magistério por meio de visão ampla do processo formativo [...] possibilitando as condições para o exercício do pensamento crítico, a resolução de problemas, o trabalho coletivo e interdisciplinar, a criatividade, a inovação, a liderança e a autonomia (BRASIL, 2015). (Grifo nosso)
}

Considerando toda amplitude do texto normativo da formação de professores e o fato de este ser resultado de um amplo processo de discussão, como atestado nas considerações introdutórias do Parecer CNE/CP n 2/2015, estas referências a uma educação crítica e à formação para autonomia 


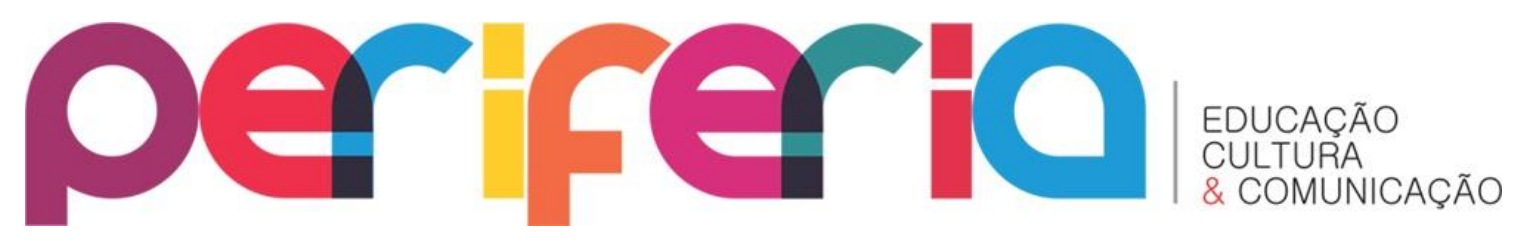

parecem insuficientes para contrapor-se ao conjunto de outras políticas que regulam a prática docente em sentido oposto à autonomia, como veremos na seção seguinte.

Sabemos que a produção de políticas educacionais é território de conflito e de disputa de poder, assim questionamos como a autonomia, enquanto aspecto relevante na formação e prática docente vem sendo significada nas políticas educacionais mais recentes. Nesse sentido, pretendemos refletir sobre as políticas de avaliação em larga escala implementadas pelo MEC percebendo como elas afetam os sentidos de autonomia escolar, notadamente a autonomia docente.

\section{POLÍticas dE AVALIAÇÃO EM LARGA ESCALA E A REGULAÇÃO DO TRABALHO DOCENTE}

As reformas educacionais ocorridas no Brasil a partir de 1990, sob o argumento de melhoria da qualidade do ensino e de adequação dos currículos às novas demandas da sociedade globalizada, têm gerado críticas de intelectuais por produzir novas formas de existência no âmbito escolar que se contrapõem à compreensão de educação em sentido mais amplo. Em relação à formação docente, essas políticas,

[...] buscaram depauperar a formação intelectual dos professores, propondo uma assepsia ideológica que enleia o sentido da realização daquilo que é próprio da profissão, ou seja, possibilitar ao aluno da escola pública a apropriação do conhecimento socialmente produzido e sua formação como sujeito histórico, sua formação humana ( SHIROMA; EVANGELISTA, 2015, p.91).

Desse modo, no texto das reformas, o discurso tem privilegiado a rarefação da formação docente e uma concepção de qualidade educacional nos termos do Banco Mundial, entendida como qualidade de nível mundial (SHIROMA; EVANGELISTA, 2015); além de um currículo positivo (GIROUX, 


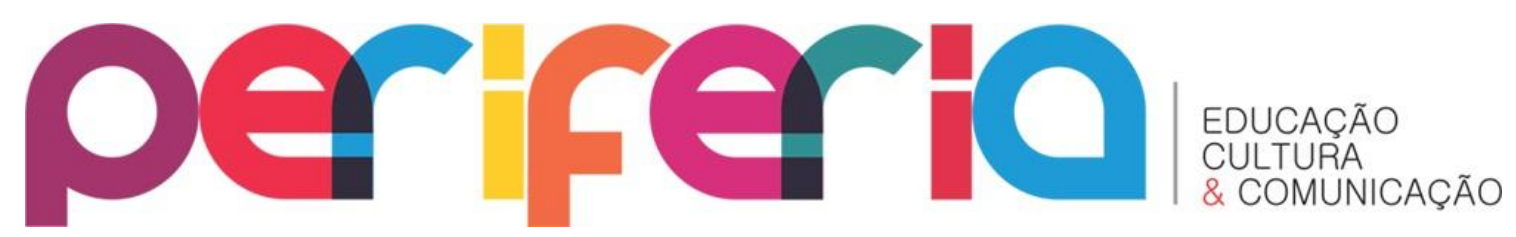

1997), regulação de professores e escolas, padronização de resultados por meio de testes e indicadores de desempenho, classificação de escolas, bonificação docente (MOREIRA, 2013), dentre outras. Nas palavras de Evangelista (2005, p. 111), acerca das reformas e seus impactos na educação

[...] engendrou-se, organicamente, um conjunto de ações materializadas num pacote de medidas direcionadas para a educação, que passariam, conforme os ditames governamentais, a ter uma função utilitária e pragmática, cujo modus operandi atenderia princípios advindos de um sistema de gestão nos moldes mercadológicos.

Nesse pacote de medidas destacam-se aquelas voltadas para criação de sistemas de avaliação para todos os níveis de ensino como o Sistema Nacional de Avaliação do Ensino Superior (SINAES), Sistema Nacional de Avaliação da educação Básica (SAEB) e Exame Nacional de Avaliação do Ensino Médio (ENEM). Acrescentamos que além dos exames nacionais alguns Estados criaram seus próprios sistemas de avaliação. Nesse sentido, a política de avaliação em larga escala tem se sobressaído em relação a muitas outras políticas educacionais pelo seu caráter altamente regulador, uma vez que os resultados das avaliações são utilizados como critério para distribuição de recursos para as escolas. A autoridade do discurso dessas políticas está no argumento da melhoria da qualidade da educação.

A esse respeito Saul (2015) questiona tal pressuposto afirmando que

[...] o poder público tem trabalhado com a suposição e expectativa de que o aumento dos índices de avaliação do rendimento escolar dos alunos, informados por mensurações do tipo IDEB, SAEB, SARESP, ANA, e o PISA, expressam a melhoria da qualidade da educação.

Concordamos com a autora ao questionar o suposto de qualidade a partir de dados produzidos por instâncias superiores como as Secretarias de Educação. Reportamos a Popkewitz (2013), que ao discutir os impactos do PISA, questiona a capacidade de dados numéricos produzirem fatos. Os fatos a 


\section{periferio}

que $\mathrm{o}$ autor se refere dizem respeito à categoria de qualidade deduzida a partir de um número e como esses fatos produzem discursos de políticas educacionais. Ademais, o sentido de qualidade tem sido amplamente questionado posto que tomado, geralmente, em sentido absoluto desconsiderando a disputa de sentidos existente na educação.

0 potencial regulador advindo dos resultados das avaliações produzem os mais diversos efeitos como a preocupação das instituições superiores de ensino focarem as atividades curriculares a partir do que é cobrado nas provas do ENADE, reformulação curricular na educação básica, ingresso no ensino superior a partir do ENEM e distribuição de recursos financeiros (CASTILHO; GONÇALVES; MARTINS, 2013). Nesse sentido, autores como Freitas (2014) e Saul (2015) afirmam que o sentido de avaliação formativa ficou totalmente alijado das políticas de avaliação em detrimento de uma ótica avaliativa que atende preceitos neoliberais alinhados à racionalidade de mercado baseada,

[...] na imitação da organização do trabalho da iniciativa privada, onde o controle do processo recebe atenção privilegiada a partir da padronização e automação das atividades, tornando o trabalhador um apêndice substituível da máquina e seu desempenho monitorado por indicadores de qualidade que, se atingidos, autorizam recompensas definidas e contingentes aos índices (recompensas sociais e financeiras). (FREITAS, 2014 p. 1093).

Nesta lógica há um redimensionamento dos sentidos do processo escolar em que categorias como currículo, gestão, aprendizagem, prática docente são ressignificadas na lógica da performatividade (BALL, 2010). De acordo com Ball, performatividade está relacionada à gestão de sistemas na perspectiva neoliberal, porém alcança a dimensão de gestão da subjetividade dos indivíduos. Nesse sentido, as regras da performatividade são incorporadas e assumidas pelos indivíduos que passam a operar de modo performático na gestão "dentro de um arcabouço de julgamento no qual se encontra a definição de 'aperfeiçoamento' e efetividade, determinados para nós e 'indicados' por medidas de qualidade e produtividade” (BALL, 2010, p. 487). 


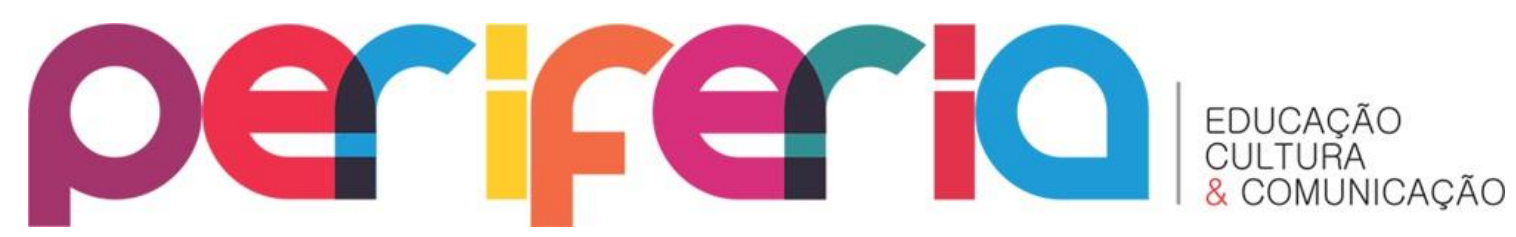

Uma das implicações dessa ótica para escola é o sentido de autonomia, pois “o indivíduo autogerenciado e a organização autônoma são produzidos nos interstícios de performatividade através de auditorias, inspeções, avaliações, autorrevisões, garantia de qualidade, avaliações de pesquisa, indicadores de resultados etc." (BALL, 2010, p. 487).

Nesse contexto, os sentidos de educação numa perspectiva crítica e de autonomia docente são rigorosamente afetados ou mesmo destituídos de sentido enquanto uma categoria válida, pois a escola passa a funcionar para responder às exigências dos exames. Essa demanda direciona o ensino e o currículo, privilegiando aquelas disciplinas e conteúdos que serão "cobrados" nos testes. O professor é desapropriado do processo de planejamento, pois em muitos casos já recebe pacotes metodológicos para executar. Retomando Freitas,

Hoje é fato visível nas escolas que a avaliação externa orienta e determina os objetivos e a extensão das disciplinas (em especial Português e Matemática, mas não menos as demais disciplinas, pois que interfere nos tempos que a escola permite dedicar a estas). A repercussão nas outras categorias pedagógicas vai se estabelecendo por meio da pressão crescente das avaliações externas [...] (FREITAS, 2014 p. 1094).

A padronização de sujeitos, docentes e discentes, figura como consequência principal dessas medidas, encobertas por significantes, como democratização do conhecimento, qualidade, professor competente, currículo etc, tomados, em geral, em sentido absoluto e de difícil contestação (SHIROMA; EVANGELISTA, 2015). O professor como intelectual transformador é categoria obsoleta, posto que não é necessário refletir sobre a própria prática. Educação escolar se resume à produção dos resultados almejados nos testes que classificarão as escolas em rankings que garantam aos professores um melhor salário e às famílias uma opção de escola para matricular seus filhos. 


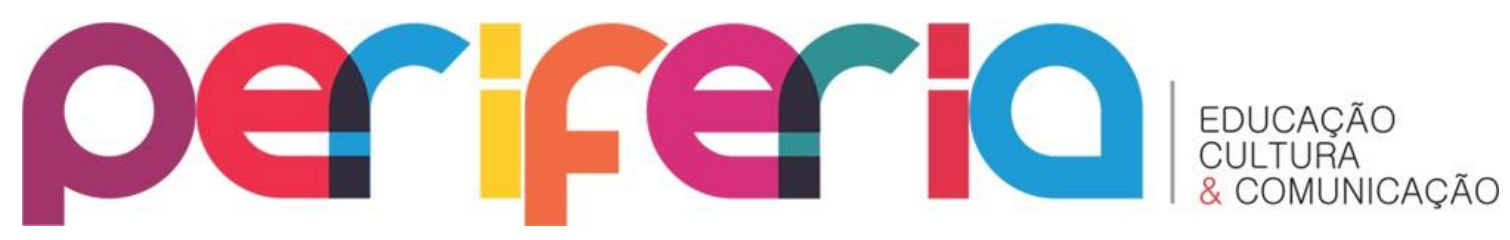

Sobre esse aspecto Shiroma e Evangelista (2015, p. 103) afirmam que "talvez possamos concluir que a concepção de autonomia brandida das entranhas do capital não se preste a pensar o trabalho do professor como autônomo nem o aluno como capaz de desenvolver autonomia", daí os pacotes de mercadoria educacional levados às escolas para os professores apenas executarem.

A defesa de uma educação numa perspectiva crítica que permita formação de sujeitos autônomos nos impele a refletir sobre os desafios para o enfretamento dos determinismos da regulação na educação. Pensar a formação de professores poderia ser uma via, porém esta se encontra fortemente regulamentada em um duplo processo. De um lado os documentos legais específicos da formação docente de outro a regulamentação definida para as escolas e currículos da educação básica que engendram uma prática cotidiana que termina por refletir na formação dos professores com maior ou menor grau de influência, a depender da autonomia das instituições formadoras.

Não obstante acreditamos ser possível a articulação de forças de resistência a tais processos de regulação, concebendo a escola como espaço de resistência e de construção de práticas com alguma autonomia. Na seção seguinte traçamos algumas reflexões sobre esse aspecto.

\section{POSSIBILIDADES DE ESCAPE E CONSTRUÇÃO DA AUTONOMIA DOCENTE}

A percepção da educação como uma prática inserida num contexto de lutas de poder nos permite reconhecer os processos de regulação como manifestação dessas lutas. Trata-se de uma disputa por hegemonia de concepções e práticas educativas. O reconhecimento das forças constituídas no cenário atual nos impele a pensar em estratégias para o enfretamento da regulação do cotidiano escolar em face da garantia de alguma autonomia. Talvez uma das frentes de batalha esteja na construção/reconstrução cotidiana do ambiente escolar como espaços coletivos e de participação onde 


\section{periferio}

professores e alunos possam refletir e problematizar sobre o significado de suas práticas curriculares.

Para esta reflexão apoiamo-nos no conceito de esfera pública de Henri Giroux. A noção de esfera pública que o autor discute advém, conforme ele informa, das esferas públicas clássicas: agremiações políticas, associações de bairros, casas de publicação, cafés, espaços oportunos para dialogar, debater, opinar sobre questões diversas e criação de uma força política. Eram espaços de liberdade onde as pessoas falavam sobre as questões do cotidiano e política produzindo discursos dos grupos subordinados, possibilitando o surgimento de intelectuais orgânicos (GIROUX, 1997).

Por essa analogia, pensar a escola como esfera pública é defender que a partir das interações entre seus membros, discutindo sobre seus sentimentos, experiências, perspectivas e sentidos de educação defendidos, possa ser construído um discurso de autoafirmação enquanto categoria educativa. Giroux propõe o resgate do sentido original de esfera pública para os tempos atuais e defende que

As instituições de formação de professores precisam ser concebidas como esferas públicas. Tais instituições, na forma como atualmente existem, são prejudicialmente desprovidas de consciência social. Como resultado, é preciso desenvolver programas nos quais os futuros professores possam ser educados como intelectuais transformadores que sejam capazes de afirmar e praticar o discurso da liberdade. (GIROUX, 1997, p. 196)

Pelo exposto, as instituições de ensino cumprem adequadamente sua função, quando os discursos nelas produzidos são voltados para um conhecimento crítico da realidade social, ou seja, para o reconhecimento das contradições sociais e relações de poder que geram a opressão e os mecanismos de luta para libertação, no sentido freireano. Esse discurso não pode ser implantado na escola de fora para dentro, precisa ser construído no seu interior como resultado da interação entre os sujeitos constituintes da instituição. Giroux critica o pouco espaço atribuído ao político na formação de 


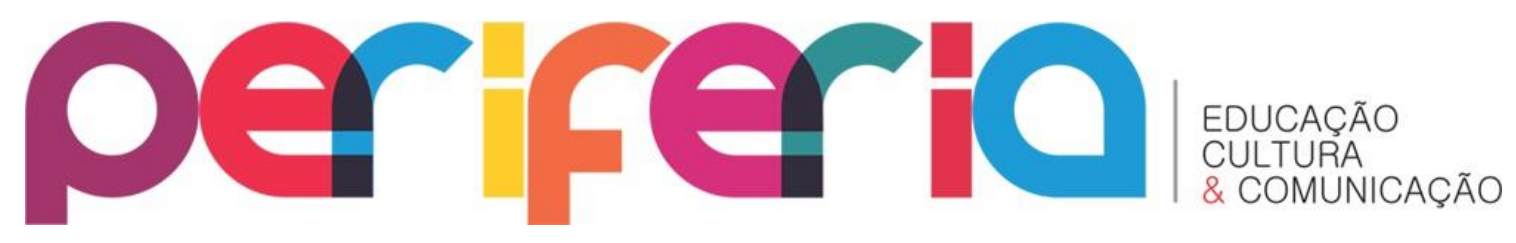

professores argumentando o quanto isso fragiliza a formação do professor ao não permitir a constituição de esferas públicas. Para ele "os programas de educação de professores poucas vezes estimulam os futuros professores a assumirem seriamente o papel de intelectual que trabalha no interesse de uma visão de emancipação" (GIROUX, 1997, p. 198).

0 autor reconhece, no entanto, que o discurso pedagógico que caracteriza o trabalho docente possui natureza contraditória que visa à padronização do processo escolar e à separação entre concepção e execução. Neste sentido, aspectos como finalidade da escolarização, cotidiano escolar, podem ser submetidos ao questionamento radical permitindo a criação de um discurso mais radical favorável ao fortalecimento da categoria, pautado na inclusão de narrativas de alunos e professores (GIROUX, 1997). Esse discurso produzido a partir das vivências desses sujeitos, tanto na escola como fora dela, possibilitaria a construção de uma contraesfera pública democrática. Giroux trabalha o conceito de contraesfera pública a partir do conceito de contra-hegemonia, pois implica crítica, mas também criação de alternativas de lutas. "Como domínio reflexivo da ação política, a contra-hegemonia transfere a natureza característica da luta do terreno da crítica para o terreno coletivamente construído da esfera contrapública" (p. 199).

Assim, o discurso produzido no contexto da contraesfera pública fortalece os professores para enfretamento das contradições presentes no cotidiano escolar, pois "[...] as escolas são, de fato, esferas controversas de que incorporam e expressam uma disputa acerca de que formas de autoridade, tipos de conhecimento, formas de regulação moral e versões do passado e futuro [...]" (p. 162). Por esta razão, a construção da autonomia é disputada e nunca absoluta, posto que construída numa luta de poder. Esta natureza do trabalho docente exige profissionais formados com ampla compreensão política capaz de cultivar a luta da possibilidade no ato educativo. Giroux (1997) salienta que a teoria educacional radical não tem dado atenção suficiente à formação docente, "o que destituiu os professores estudantes de uma estrutura teórica necessária para compreender, avaliar e 


\section{periferio}

afirmar os significados socialmente construídos por seus estudantes acerca de si mesmos e da escola". (p. 200).

Portanto, uma estratégia de resistência à regulação e normatividade curricular, que inibe a autonomia docente precisa ser pensada em termos de participação e coletivo voltada para um autoconhecimento de si, da instituição, da comunidade que faz parte criando significados que permitam afirmar e reafirmar suas identidades e fortaleça seu discurso no enfrentamento do discurso oficial.

Confrontar o discurso nas políticas educacionais não é tarefa fácil, pois em geral este utiliza termos e argumentos que vão ao encontro do imaginário comum, sendo, portanto, muito sedutores. Nesse sentido, é necessário mostrar que palavras como: qualidade, escola para todos, eficiência, e democratização do conhecimento, inclusão, justiça, dentre outros, não absolutas. Uma estratégia é situá-las historicamente, “[...] discutir suas contradições, mostrando que tais metas e princípios exigem explicações dos múltiplos sentidos que assumem" (SHIROMA; EVANGELISTA, 2015, p. 99).

As autoras explicitam o risco dos intelectuais apenas contraporem-se a tal discurso e terminarem sendo vítimas da gestão dos silêncios, utilizado contra aqueles que se opõem às políticas. Portanto,

[...] para escaparmos dessa armadilha é necessário recorrermos a outros referentes para explicar o sentido dos termos nos projetos societários em disputa. A opção metodológica para enfrentar esse desafio talvez seja reconstruir os sentidos históricos dados pelo capital para educação e seus professores, para depois desconstruí-los criticamente. (SHIROMA; EVANGELISTA, 2015, p. 99).

Essa ação requer diálogo, debate. As autoras destacam também o papel dos professores como intelectuais organizadores da cultura, bem como a mobilização de diversos agentes da categoria educacional para realização desse processo, como os sindicatos, organizações e intelectuais (SHIROMA; EVANGELISTA, 2015). Do mesmo modo, Giroux (1997) afirma que a discussão da 


\section{periferio}

escola como contraesfera pública democrática e os professores como intelectuais nesse processo não pode ser feita alheia às demais instituições sociais.

O pressuposto da possibilidade de constituição da autonomia docente, ainda que limitada, em um ambiente escolar fortemente regulado pelas políticas educacionais está subsidiado também na concepção de produção de políticas de Stephen Ball. Lopes (2016) discute a abordagem do ciclo de políticas de Ball como importante para questionar o sentido de verticalidade na produção das políticas, visto que nessa abordagem é possível pensar a produção das políticas a partir de três contextos: o de influência, o da produção de textos e o da prática. A autora ressalta a relevância das ideias de política como prática, como texto e como discurso, advindas dessa abordagem, pois permitem "[...] o questionamento às usuais compreensões sobre política educacional que reduzem a escola ao espaço de implementação" (LOPES, 2016, p. 4).

Desse modo, é possível compreender o sentido de pôr a política em ação, a Teoria da Atuação, como definem Ball, Maguire e Braun (2012 apud LOPES, 2016). Lopes (2016) mostra que a compreensão da política na lógica da Teoria da Atuação de Ball envolve três aspectos: "o material (aspectos físicos da escola, contextuais), o interpretativo (o problema da significação), e o discursivo" (p.5). O processo de compreensão das políticas em ação, produzindo práticas e sujeitos, é feito na relação desses três aspectos. Lopes (2016) aponta, a partir dessa Teoria, a dupla possibilidade produtiva do professor. "Os professores oscilam, portanto, entre dinâmicas criativas e submissas, entre a possibilidade de escapar dos discursos políticos impositivos e aquiescer diante deles”. (p.6). A autora pondera que a decisão dos professores não segue um direcionamento apenas individual, mas depende também do contexto da instituição.

Para nossa discussão aqui é importante salientar que as políticas, mesmo reguladas, podem ser formuladas/reformuladas em diversos contextos, inclusive no contexto da prática escolar. Portanto, consideramos a criação de 


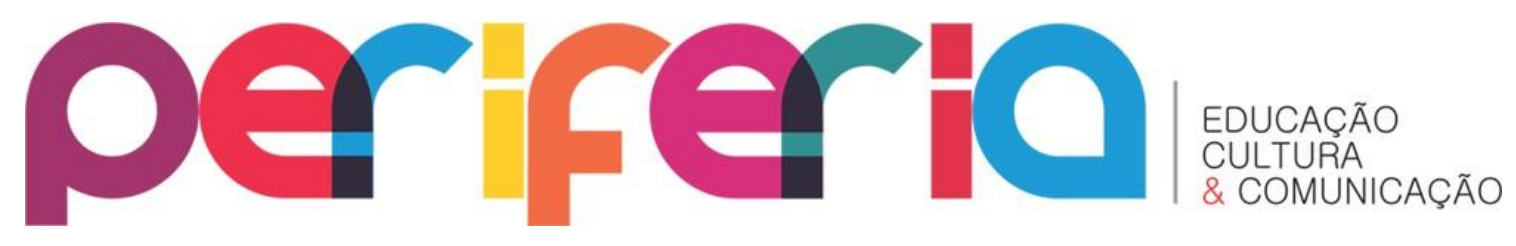

espaços de discussão nas escolas na perspectiva de contraesfera pública produtora de um contexto institucional potente para criação de políticas públicas referendadas pelos seus sujeitos praticantes.

\section{CONSIDERAÇÕES FINAIS}

As políticas educacionais adotadas no país nas últimas décadas estão fundamentadas nos princípios neoliberais para educação, criando novos referenciais de atuação escolar e docente numa tentativa de forjar um modelo de homem competitivo para, argumentam seus defensores, enfrentar os desafios do mundo atual. Shiroma e Evangelista (2015) argumentam que se trata de um controle de resultados em nome da qualidade; um controle do que se ensina e aprende numa perspectiva de controle do sujeito formado. Para isto há uma revisão no modo de funcionar da escola, priorizando a lógica gerencial de mercado com ênfase nos resultados e metas a serem alcançados em testes padronizados.

Essa influência neoliberal nas políticas educacionais recentes tem recebido muitas críticas de educadores que estudam o tema, sobretudo, no campo da formação docente. Neste trabalho, abordamos uma das consequências que consideramos nefasta na lógica neoliberal para educação, a subtração da autonomia nos processos escolares que afeta a prática docente, os currículos e formas de organização do processo escolar.

Entendemos que há um cenário social de intensas disputas de concepções de educação e a formação e atuação do professor faz parte dessas disputas. Defendemos que a formação do educador numa perspectiva crítica representa uma possibilidade de enfrentamento da regulação que as escolas têm sofrido no sentido de permitir, ainda que relativamente, a autonomia no processo escolar. Fazemos isso argumentando a necessidade de transformação das escolas em esferas públicas e acreditando com Ball na possibilidade de produção das políticas em diversos contextos, inclusive o da prática. 


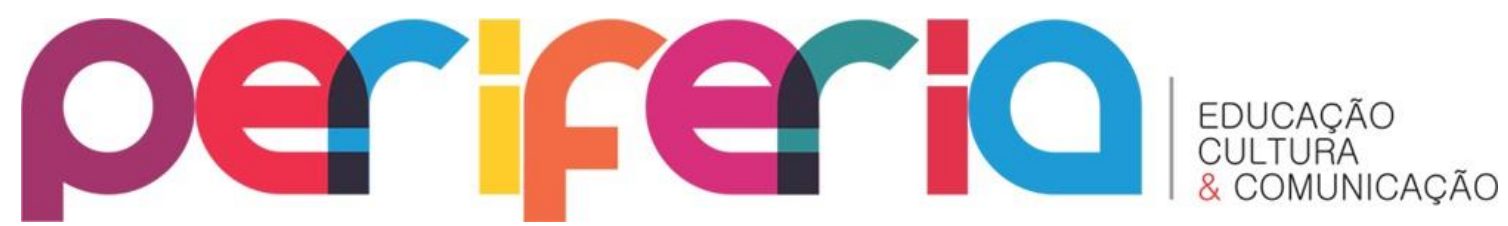

\section{REFERÊNCIAS BIBLIOGRÁFICAS}

APPLE, M. W.; AU, W.; GANDIN, L. A. Educação crítica: análise educacional. Trad. Vinicius Figueira. Porto Alegre. Artmed, 2011.

BALL, S. J. Vozes/Redes Políticas e um Currículo Neoliberal Global. Espaço do Currículo. v. 3, n. 1 p 485-498, março-setembro de 2010. Disponível em: <http://periodicos.ufpb.br/ojs/index.php/>. Acesso em: 07 nov. 2016.

BRASIL. Ministério da Educação. Conselho Nacional de Educação. Parecer CNE/CP nº. 2 de 9 de junho de 2015. Brasília, DF, 2015.

BRASIL. Ministério da Educação. Conselho Nacional de Educação. Resolução CNE/CP nº. 2 de 1 de julho de 2015. Brasília, DF, 2015.

BRZEZINSKI, I. Profissão professor : identidade e profissionalização docente. Brasília, DF: Plano Editora. 2002.

BORGES, L. F. F. Um currículo para formação de professores. In : VEIGA, I. P. A. e SILVA, E. F. da. (Orgs.). A escola mudou. Que mude a formação de professores! 3. ed. Campinas, SP. Papirus, 2012.

CASTILHO, M. L; GONÇALVES, E; MARTINS, C. R. B. Avaliação em larga escala e ensino de graduação: reflexões sobre as práticas pedagógicas. In: RAMOS, K. M. da C; VEIGA, I. A. P. (Orgs.). Desenvolvimento profissional docente:

currículo, docência e avaliação na educação superior. Recife, Ed. UFPE, 2013.

EVANGELISTA, A. M. Universidade pública e formação docente na reforma educativa brasileira. In: ALBUQUERQUE, L. B. (Org.). Currículos contemporâneos. Fortaleza. Ed.UFC, 2005.

FREIRE, P. Pedagogia da autonomia: saberes necessários à prática educativa. 19. ed. São Paulo: Paz e Terra, 1996.

FREIRE, P. Pedagogia do oprimido. 17. ed. Rio de Janeiro: Paz e Terra, 1987.

FREITAS, L. C. de. Os reformadores empresariais da educação e a disputa pelo controle do processo pedagógico na escola. Educação Sociedade, Campinas, SP, v. 35, n. 129, p. 1085-1114, out.-dez, 2014. Disponível em: <http://www.scielo.br/pdf. . . Acesso em: 16 out. 2016.

GADOTTI, M. Escola cidadã. 4. ed. São Paulo: Cortez, 1999. 


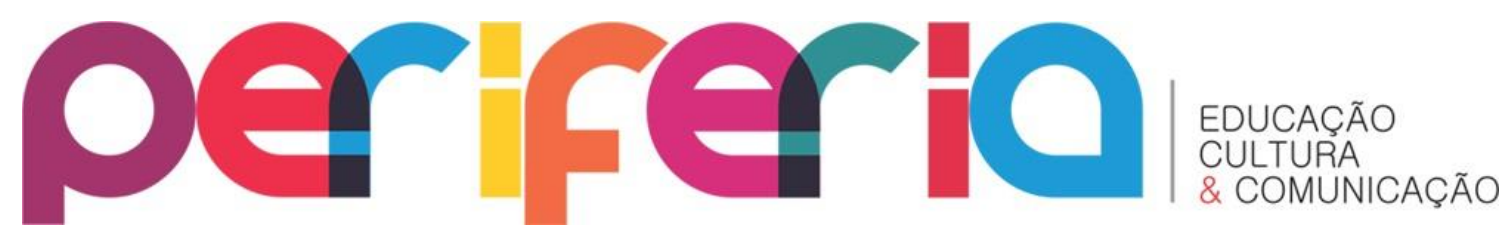

GIROUX, H. A. Os professores como intelectuais: rumo a uma pedagogia crítica da aprendizagem. Trad. Daniel Bueno. Porto Alegre, RS: Artes Médicas, 1997.

LOPES, A. C. A. Teoria da atuação de Stephen Ball: e se a noção de discurso fosse outra? Revista Archivos Analíticos de Políticas Educativas. v.24 n. 25. fev. 2016. Disponível em: <http://epaa.asu.edu/ojs >. Acesso em: 20 jun. 2016.

MOREIRA, A. F. B. Currículo e gestão: propondo uma parceria. Ensaio: avaliação, política públicas em educação. Rio de Janeiro, v. 21, n. 80, p. 547562, jul./set. 2013. Disponível em: <http://www.scielo.br/pdf/ensaio/>. Acesso em: 20 set. 2016.

ORTIGÃO, M. I; PEREIRA, T. V. Homogeneização curricular e o sistema de avaliação nacional brasileiro: o caso do estado do Rio de Janeiro. Educação, sociedade e culturas. v. 47, p. 157-173. Disponível em:

<http://www.fpce.up.pt/ciie/sites/default/files>. Acesso em: 26 out. 2016.

POPKEWITZ, T. S. PISA: números, estandarización de la conducta y La alquimia de las matérias escolares. Professorado. Revista de curriculum y formación de professorado. Disponível em:

<http://recyt.fecyt.es/index.php/profesorado/article/>. Acesso em: 26 set. 2016.

SAUL, A. M. Na contramão da lógica do controle em contextos de avaliação: por uma educação democrática e emancipatória. Educação e pesquisa. São Paulo, v. 41, n. especial, p. 1299-1311, dez., 2015. Disponível em: $<$ http://www.scielo.br/pdf $>$. Acesso em: 7 jul. 2016.

SILVA, T. T. da. Documentos de identidade: uma introdução às teorias do currículo. 3. ed. Belo Horizonte: Autêntica, 2010.

SHIROMA, E. O; EVANGELISTA, O. Formação humana ou produção de resultados? Trabalho docente na encruzilhada. Revista contemporânea de educação, vol. 10, n. 20, jul./dez. de 2015. Disponível em:

$<$ https://revistas.ufrj.br/index.php/rce/articcle>. Acesso em: 18 out. 2016.

VEIGA, I. P. A. A aventura de formar professores. 2. ed. Campinas, SP: Papirus, 2012.

; SILVA, E. F. da. (Orgs.). A escola mudou. Que mude a formação de professores! 3. ed. Campinas, SP: Papirus, 2012. 